\title{
Educación mediática y periodismo de calidad. Propuesta de medición y evaluación en informativos de la televisión pública ${ }^{1}$
}

\section{Media Education and Quality Journalism. Measurement and Evaluation Proposal in Public Television News}

Concha Pérez Curiel. Universidad de Sevilla

Sergio Luque Ortiz. Universidad de Sevilla

Recibido: 13-VI-2014 - Aceptado: 26-IX-2014

Resumen:

La investigación considera como objetivo general avanzar en el estudio de la Educación Mediática como garante de la calidad informativa. Se presenta una fórmula de medición objetiva de los contenidos de los medios escritos, audiovisuales y digitales a través de una ficha con indicadores de calidad (basada en el Valor Agregado Periodístico). Tras la primera fase destinada a la evaluación de las fuentes en la prensa local se propone ahora medir los niveles de cualificación en los informativos de cadenas públicas como Televisión Española y Canal Sur Televisión. La aplicación de la ficha permitirá que los medios de comunicación comprueben si un producto reúne las condiciones para convertirse en "marca de referencia" y reflexionen tras los resultados sobre su responsabilidad.

Palabras Clave:

Educación Mediática, calidad, contenido, valor agregado periodístico, evaluación.

Abstract:

The investigation considers as general aim the advance on the study of the Media Education as guarantor of the quality information. It is presented a formula to make an objective measure of the contents of the writing, audio-visual and digital media by a card with quality indicators (based on the Added Journalistic Value). After the first phase destined to the evaluation of the sources in the local press it is proposed now to measure the level of qualification in the news of public channels like Television Española or Canal Sur Television. The use of this register will allow the media to verify if the product assembles all the conditions to be a reference brand and also about their social responsibility.

KeyWords:

Media Education, quality, content, value added journalism, evaluation.

1 Proyecto: Periodismo de Calidad versus nuevos formatos periodísticos digitales. Diseño de una herramienta de validación. Grupo de investigación Estudio de Medios para un Periodismo de Calidad (SEJ-001). 


\section{Introducción}

Educación Mediática y Periodismo de Calidad siguen siendo conceptos abstractos y cuestionados. Desde las esferas institucionales y mediáticas existe un discurso político de compromiso, actuación inmediata y reflexión sobre la responsabilidad social. Sin embargo, el trabajo de organismos reguladores, de colectivos y sobre todo de investigadores demuestra que existen factores que impiden y obstruyen una actitud de cambio en el tratamiento periodístico de la información.

La ausencia de una formación especializada y el entorno laboral del periodista sometido a presiones de economía, productividad o ránkings de audiencia han podido ser causas de la pésima calidad en la producción periodística. Por tanto, urge evaluar los niveles de calidad y diseñar herramientas que ayuden a los medios a conseguirla.

"La espectacularización de las noticias, la telebasura o el infoentretenimiento por un lado, y la crisis de la prensa, así como la adaptación de los periódicos a las diversas aplicaciones digitales, por otro, han situado la calidad como uno de los temas claves del debate sobre los medios de comunicación en las últimas décadas. Su protagonismo, sin embargo ha sido paradójico, especialmente en el contexto español, más para recalcar la ausencia o degradación progresiva, que para plantear cuáles son los criterios que rigen una información de calidad" (Gómez Mompart, J. L. y Palau Sampío, D., 2013: 17).

Que la calidad de la información periodística está socialmente cuestionada y que los medios están perdiendo credibilidad son hechos comprobados. Las conclusiones del estudio The Quality and Independence of Bristish Journalism (en Lewis et. al., 2007) realizado por un grupo de profesores de la Universidad de Cardiff muestran las pésimas condiciones de producción y de trabajo de los periodistas. Según el informe, menos de cada cinco artículos analizados se basa fundamentalmente en información propia (2007:25), la mayor parte de los temas están respaldados por una sola fuente y solo en uno de cada cinco casos la voluntad de contextualizar o verificar la información se ha hecho de forma coherente y significativa (2007:26). Las condiciones de economía y productividad afectan a los niveles de calidad de los contenidos.

Se trata de factores que influyen negativamente en el acceso del periodista a las fuentes y que revierten en un control cada vez mayor de las mismas sobre lo que publican los medios. La producción de noticias no puede evitar recurrir a las fuentes ni escapar de su influjo. La centralidad de las fuentes es tal que permite afirmar que sin ellas no hay periodismo. Ello unido a su capacidad para condicionar el resultado final de una noticia las vincula directamente con la calidad informativa (Gutiérrez Coba, L., 2006: 29-56).

Pero la calidad informativa a su vez puede verse cuestionada por una selección condicionada de las fuentes en la que primen sus propios intereses y los del medio. Por ello la selección de las fuentes reviste una gran complejidad. En este sentido, 
la facilidad y rapidez de acceso a la información, la constancia y la frecuencia a la hora de suministrar los datos, la fiabilidad y veracidad de estos o la autoridad se configuran como criterios preferentes.

Por encima de indicadores de calidad como pueden ser el estatus profesional, la verificación, la transparencia, la relevancia, la credibilidad o el pluralismo, la dinámica periodística se ha orientado hacia el predominio de las fuentes oficiales y gubernamentales en las noticias. Todo ello se traduce en una dependencia de las fuentes institucionales, por un lado, y en una estructura de fuentes centrada en un número reducido de actores, procedentes mayoritariamente del ámbito político.

Esta tendencia provoca la supremacía de las interacciones entre los periodistas y los actores políticos y que la actualidad periodística se configure como un instrumento al servicio del mantenimiento del status quo político-social. La gestión de fuentes se convierte, así, en un reflejo de la estructura de poder de una sociedad.

Los últimos estudios e investigaciones sobre Educación Mediática han centrado su atención en conocer si es posible medir la calidad periodística con métodos empíricos y cuantitativos. Una de las primeras opciones de análisis procede de un equipo de investigadores de la Pontificia Universidad Católica de Chile (2001) que desarrolló un patrón de medición denominado Valor Agregado Periodístico (VAP) entendido como "la capacidad que tiene el periodista de entregar y procesar información sin distorsionar la realidad, seleccionando y jerarquizando provisionalmente lo que es noticia y las fuentes involucradas en el hecho" (VV.AA., 2001:114).

Otros equipos de investigación, más que apelar a la labor de los profesionales, apuestan por la percepción de la audiencia como elemento de referencia. En esta línea, De la Torre y Téramo (2005) proponen un indicador de Percepción de la Calidad Periodística (PCP). Gómez Mompart después de evaluar las periodísticas de calidad de dos docenas de medios internacionales (prensa, radio y televisión) agrupa los principios para un periodismo de calidad en cuatro apartados:

A. Cuestiones éticas y deontológicas.

B. Fuentes y documentación para las informaciones.

C. Tratamiento y desarrollo de las noticias.

D. Relaciones con la opinión pública (2001:34).

Por su parte, la red de Periodismo de Calidad de México (VV.AA., 2006: 36-37) planteó una Propuesta de Indicadores para un periodismo de calidad: indicadores que dependen del trabajo del periodista (transparencia, verificación, investigación y derechos y obligaciones de los periodistas y sus directivos) e indicadores que dependen del entorno del periodista (código ético, defensor del lector, observatorios civiles, equidad en la asignación de publicidad y derecho y acceso a la información). 
Cualquier profesional de la información experimentado puede reconocer un buen trabajo periodístico frente a otro de baja o poca calidad, pero si quiere lograr que los medios alcancen la excelencia será necesario pensar en un método que establezca parámetros medibles de calidad.

Si el objeto de estudio son los informativos de televisión de cadenas nacionales la consigna es que este medio está cada vez más influido por el infoentretenimiento o tendencia de los medios a presentar la información como espectáculo, con el fin de servir de gancho para captar y mantener la audiencia. El sector audiovisual público se ha visto obligado a renovar las estrategias de producción y el interés humano ha suplantado al interés público así como los sucesos y deportes reciben mayor atención que las noticias económicas o sociales. El hecho de desvirtuar la información y la mezcla de géneros favorecen que los estilos actuales desdibujen las fronteras entre el periodismo y el sensacionalismo.

Unido al concepto de calidad y también recogido como principio del presente estudio se encuentra la ética como actitud del medio ante los acontecimientos. Por ello es interesante hacer referencia al proyecto dirigido por S. Alsius "Ética y excelencia informativa. La deontología periodística frente a las expectativas de los ciudadanos” que tiene como objetivo contrastar hasta qué punto los profesionales de la información comparten las normas existentes (Alsius, 2011: 27-58).

Una radiografía de los informes publicados demuestra pues que el interés de los medios por reconducir la situación es cuestionable y muy diferente según qué estructuras políticas, económicas y mediáticas les controlan. Quizás, abrumados por la ineludible tarea de formar a los ciudadanos se ha descuidado una estrategia clave: educar a los medios en la creación de una marca de referencia.

Esto es, mostrarles una herramienta, una plantilla de medición que les permita comprobar qué tipo de producto ofrecen a los públicos y en qué medida pueden mejorarlo para convertirse en ranking de audiencias y ventas conjugando calidad, cantidad y precio. Nuestra propuesta aporta una novedad al estudio que consideramos de relevancia: que los profesionales mediáticos conozcan los criterios de medición de calidad de su producto. La calidad será un sello de distinción del programa, de la cadena, del operador, porque al final, terminará siendo la exigencia de los ciudadanos que seleccionarán información, formación y entretenimiento de calidad frente a formatos sensacionalistas y faltos de deontología periodística.

El poder de decisión asociado a la audiencia debe ampliarse. La audiencia decide sobre calidad frente a cantidad, sobre información frente a desinformación, sobre medios comprometidos -al menos los públicos- y medios mercantilistas y promotores de las estructuras de poder. La calidad importa y es posible medirla. Lejos de pasar desapercibida empieza a instalarse como requisito entre los medios de comunicación y la opinión pública que ya han decidido incluirla en su escala de valores. 


\section{Del Sujeto al objeto de la investigación}

Ciudadanos y periodistas forman un tándem como focos protagonistas dado que ambos deben exigirse y exigir la calidad del producto, unos como productores y otros como consumidores. Así mismo, ambos necesitan de la educación mediática como vía de formación que les permita evaluar y decidir sobre el tipo de producto, de programa que se pretende crear (desde los medios) o consumir (público infantil, adolescentes, formatos educativos, de entretenimiento, informativos, de debate...). Es clave formar a los profesionales mediáticos en calidad a partir de datos verificados científicamente.

Cuando se habla de Educación Mediática, la ciudadanía es un foco que precisa de una formación para "digerir" la cantidad de contenidos diversos que inundan su día a día. Pero, ¿̇saben los profesionales de los medios, los periodistas, qué es calidad mediática, cómo se puede detectar, qué criterios de base tiene que cumplir un programa para alcanzar la marca registrada? ¿Saben que la calidad es compatible con el interés por un producto? ¿Saben que es posible mantener la continuidad y las audiencias sin prescindir de la calidad?

El pacto por un periodismo de calidad es necesario y quizás la única vía para responder a la multiplicidad de cadenas con productos que persiguen el beneficio de programas basura, información dirigida o desinformación, absoluto modelo de propaganda mediática. En este apartado se sitúan también la escuela, la familia, las instituciones y los organismos reguladores que deben coordinarse en un pacto social por la salud de los consumidores mediáticos y la exigencia de la calidad periodística.

Los organismos reguladores de los medios les trasladan las quejas de los espectadores, las decisiones que toman, las recomendaciones... pero es fácil mirar para otro lado cuando hay programas que rallan en la vulgaridad, el sensacionalismo y la provocación, que siguen ocupando la cúspide de los rankings de audiencias. Sin embargo, por encima de las sanciones a los medios existe una fórmula para que aprecien que con los mismos recursos es posible fabricar calidad y rescatar a los públicos

\subsection{Objeto de la investigación}

La educación mediática como fórmula de base para instalar un criterio de calidad periodística entre los medios y los ciudadanos. Con la aprobación de la Ley del Estado 7/2010, de 31 de marzo, general de la comunicación audiovisual, la contribución a la alfabetización mediática de la ciudadanía se convierte en obligación, tanto para los poderes públicos como para los prestadores del servicio de comunicación audiovisual.

La Directiva 2010/13/UE del Parlamento Europeo y del Consejo del 10 de marzo de 2010 sobre Servicios de Comunicación Audiovisual define la alfabetización mediática como "las habilidades, los conocimientos y las capacidades de comprensión que permiten a los consumidores utilizar con eficacia y seguridad los medios”. Los parámetros básicos de la UNESCO 
para realizar un planteamiento adecuado de la Educación en Comunicación se basan en el aprendizaje sobre los medios de comunicación, el análisis crítico y la producción creativa, se desarrolla tanto en el ámbito de la educación formal como no formal, por tanto, afecta a niños y adultos y debe promover el espíritu de comunidad y de responsabilidad social, así como la autonomía personal.

Datos científicos demuestran que los menores son un grupo de población de riesgo sobre el que determinados programas ejercen una acción perjudicial. Los datos de audiencia indican que la franja en la que los niños ven más televisión es el prime time, momento de máximo consumo para todos los públicos. Según Vázquez Barrios, experto en televisión educativa:

"Los niños atienden más a la pequeña pantalla y cuando hay más cantidad de ellos viéndola -en miles de espectadores- no es en los horarios de programación infantil, sino en el consumo preferente, que está fuera del horario de protección establecido en el Código de Autorregulación y que exhibe contenidos en principio dirigidos a otros grupos de edad. En consecuencia, los menores, además de dibujos animados y programas infantiles, ven otro tipo de espacios como informativos, retransmisiones deportivas, programas de entretenimiento y sobre todo, series de ficción nacional. Es la llamada adultización de los niños” (2011:119).

En el ámbito chileno, el Consejo Estatal de TV de este país expone las siguientes conclusiones tras el análisis de 49.715 horas de programación:

- $\quad$ La programación destinada a niños y niñas menores de 12 años alcanzó un 13\% de la oferta general de TV abierta. En tanto la programación para adolescentes sólo concentró un 4,3\%.

- $\quad$ El 21\% del tiempo de consumo de los menores entre 4 y 12 años se concentró en horario para Adultos, es decir, entre las 22:00 y las 05:59 horas.

- $\quad$ Los géneros más consumidos por los niños/as fueron las Serie-Miniserie y los Informativos, 19,7\% y 19\% respectivamente.

- $\quad$ Cada persona vio un promedio de 944 horas de TV. Esto equivale a 2,6 horas diarias. Las mujeres consumieron en promedio 315 horas más que los hombres (1.098 versus 783 horas), lo que equivale a un promedio de 3 horas diarias por parte de las mujeres versus 2,14 horas por parte de los hombres.

- Los que ven más televisión son los adultos mayores, con un promedio de 4 horas y 20 minutos por día. Mientras que el grupo que consumió menos horas durante el 2010 fueron los menores entre 4 y 12 años, con un promedio de 1 hora y 45 minutos por día. 
- Los noticiarios fueron el género televisivo de mayor consumo durante el 2010 (23,7\%). Con un promedio por persona de 223 horas al año, lo que equivale a 40 minutos diarios.

- $\quad$ La oferta de programación cultural, según los criterios de contenidos establecidos por el CNTV, durante el año 2010 fue de 1,8\% (875 horas) respecto del total de horas de programación emitidas.

¿Cómo actuar ante estos resultados? Es preciso iniciar, desarrollar entre los grupos de población más susceptibles la dinámica de la formación en medios para ver y comprender la TV, para navegar por la programación mediática en la red, con garantía.

Para definir la calidad, un concepto sujeto a la abstracción, es complicado si no responde a unos criterios. Lo que puede ser de calidad para un grupo de población puede no serlo para otro, incluso entre personas, la calidad se puede entender de diferente manera. Es fundamental entonces establecer criterios de calidad de la programación audiovisual y variables que nos permitan medir esa calidad.

El tratamiento de un tema, el enfoque, la actitud del profesional que lo conduce, las fuentes con las que se contacta, el lenguaje que se utiliza, el tiempo y el espacio que se dedica, si se contextualiza y se relaciona bien la información con otros hechos, si se explican e interpretan los datos, si existe un discurso subliminal persuasivo, si se genera en los espectadores una actitud crítica o por el contrario, una actitud sumisa... en definitiva, si es una información superficial o profunda, formativa o que favorece la incultura, de interés público o sensacionalista.

También hay que analizar estas variables en función del tipo de programa evaluado: informativos, tertulias, debates, corazón, magacines, humor, deportes, ciencia, documental, periodismo de investigación y denuncia, cultura...

Otra cuestión es desvincular tópicos y estereotipos relacionados con la calidad de los medios de comunicación: por ejemplo, ver un documental o un programa de investigación es signo de una audiencia selecta, formada y rigurosa, ver una telenovela es signo de una audiencia analfabeta, ignorante y vulgar, ver un programa de deportes es cosa de hombres o corazón de mujeres, ver informativos es signo de audiencia interesada por la actualidad frente a la gente que opta por concursos o realities.

Más que por el tipo de programas, el grado de calidad se mide por el tratamiento temático y por los recursos que el profesional utiliza en su producción. Un informativo puede cumplir los mejores estándares de calidad (veracidad, contraste, transparencia, interés, actualidad...) o lo contrario (parcialidad, rumor y desinformación, amarillismo, falta de contraste...).

La radiografía social carece o alcanza mínimos en los objetivos de base. Los profesionales de los medios no entienden el concepto de Periodismo de Calidad que vinculan a veces a un periodismo especializado, no acorde con los criterios de productividad y economía, de tiempo y espacio que definen a la empresa mediática. Incluso, pueden demostrar con datos de 
audiencia el seguimiento mínimo o cero que espacios con perfil formativo alcanzan frente a los índices de otros programas con altas dosis de sensacionalismo, falacia, lenguaje vulgar, información poco o nada contrastada, que denotan la mediocridad e ignorancia de los públicos pero sobre todo la mediocridad y falta de ética de los productores.

El discurso mediático se encuentra lleno de marcas que deberían medirse cuantitativamente como la veracidad, la actualidad, el interés público, el contraste de fuentes, el enfoque, el pluralismo, el tratamiento del lenguaje, el rigor... ¿Es calidad sólo informar o también explicar y analizar causas y consecuencias de los acontecimientos? ¿Es calidad el uso de información rutinaria (agencias, notas y comunicados de prensa, ruedas de prensa...) o lo es más la documentación y producción directa del periodista?

Los medios venden un producto pero en muchos casos desconocen los porcentajes de calidad del mismo. Saber diagnosticar la mediocridad frente a la cualificación, posibilidad de cambiar las rutinas e incorporar ítems que refuercen el valor del producto, del programa, de la página web, etcétera.

El proyecto que se presenta se encuentra vinculado al Grupo de investigación de la Junta de Andalucía, Estudio de medios para un periodismo de calidad, creado en diciembre de 2010 y cuya línea de acción metodológica (análisis de contenido) se centra en crear un instrumento capaz de cuantificar el grado de calidad periodística así como llegar a unas conclusiones también cualitativas que sirvan para reconducir la acción de los medios hacia una prioridad: la educación crítica y autónoma de sus consumidores. Si medir objetivamente la calidad es posible, diseñemos unos objetivos y un método para ello.

\section{Objetivos}

Tomando como punto de partida los resultados y conclusiones obtenidos en una investigación previa sobre La calidad de los medios y el uso de fuentes periodísticas en la prensa local de referencia en España, se enuncian una serie de objetivos:

\section{Objetivo General:}

Avanzar en el estudio de la Educación Mediática como proceso garantizador de la calidad informativa en los medios de comunicación audiovisuales y comprobar los efectos en diferentes ámbitos sociales (familia, escuela y organismos reguladores de los medios).

Objetivos Específicos:

- Conocer y analizar los resultados de variables como la temática, la presencia del periodista en el lugar de los hechos, el número, tipología y contraste de fuentes, si la iniciativa de informar parte del periodista o de las fuentes o si la noticia incluye antecedentes y consecuencias, entre otros factores determinantes de calidad mediática. 
Plantear una segunda propuesta de investigación aplicada al marco audiovisual y concretamente a los informativos de dos operadores: Televisión Española, nivel nacional, y Canal Sur Televisión, a nivel autonómico.

Diseñar una ficha de medición y evaluación para conocer el trabajo periodístico y los niveles de calidad en cuanto al tratamiento de los contenidos y de las fuentes en el marco de la televisión.

Comparar la presencia/ausencia de marcas de calidad en los informativos analizados y en qué medida responden a las recomendaciones sobre Educación Mediática establecidas por los organismos reguladores.

Comprobar si los resultados del tratamiento periodístico de los contenidos y de las fuentes en la prensa coinciden o difieren con respecto al ámbito televisivo.

\section{El Método: del análisis de contenido al valor agregado periodístico (VAP)}

La democracia mediática debe permitir la elección libre, la selección de la programación sin descuidar la edad y los niveles de formación de los usuarios. El consumo de medios debe estar precedido por un aprendizaje previo que permita distinguir entre productos aptos y no aptos, que permita seleccionar y elegir entre salud o patología mediática.

La definición de la calidad mediática, basada en principios deontológicos: veracidad, contraste, coherencia y equidad tropieza con condicionamientos económicos, ideológicos y laborales-profesionales. Así, con frecuencia se designan como periodísticos productos que solo cumplen algunas condiciones de lo noticiable: ser algo novedoso, llamativo, pero omiten requisitos como veracidad, interés público, contraste, contexto. Cabe plantearse pues cómo reconocer al periodismo de calidad, cuáles deben ser sus atributos, no en la teoría, sino en los parámetros aplicables al periodismo real, al que llega a la audiencia.

El análisis de contenido es la estrategia metodológica que permitirá medir cuantitativa y cualitativamente el índice de calidad de un producto informativo, ya sea en prensa, radio, televisión o internet. El método que permite cuantificar objetivamente los niveles de calidad de los contenidos se sustenta en investigaciones previas de la Universidad Pontificia Católica de Chile y de Argentina que han utilizado el Valor Agregado Periodístico (VAP) como herramienta que permite medir unos indicadores.

Desde el enfoque de la información, la selección del tema, el tipo de fuentes, el uso del lenguaje, de los recursos gráficos e infográficos hasta el papel de productor del periodista como experto que se documenta, que contextualiza, explica, analiza y valora razonadamente los hechos... todos son factores medibles cuantitativamente para reconocer la calidad del documento impreso, audiovisual o digital y convertir en producto de desecho todo aquello que no alcance los mínimos establecidos; claro que para eso es importante contar con la connivencia de los poderes políticos y mediáticos y de los 
públicos, de la ciudadanía para superar un proceso duro de alfabetización mediática en la familia, la escuela, la calle y la sociedad en general.

A través del análisis de la calidad periodística no solo se puede determinar qué textos pueden considerarse de calidad y cuáles no. También se pueden diagnosticar y tratar los males de la calidad periodística partiendo de los propios textos y modificar las rutinas de los periodistas.

Consideramos que el método VAP (Valor Agregado Periodístico), desarrollado en la Pontificia Universidad Católica de Chile y de Argentina es un verdadero hallazgo para evaluar de un modo objetivo la calidad del trabajo periodístico y así se ha puesto de manifiesto en múltiples investigaciones. Esta metodología evalúa los textos periodísticos, centrándose en dos etapas: el proceso de selección de la noticia o gatekeeping y el proceso de creación de la misma o newsmaking basándose en la aplicación de fichas de análisis al trabajo periodístico en la fase de selección del acontecimiento y posteriormente en su proceso y jerarquización.

Rastreando los indicadores de las dos etapas de concepción del texto periodístico se descubren cuáles son las variables en las que radica su calidad. En el caso del proceso de selección se analizan indicadores de tres niveles:

a) selectividad de la noticia

b) de acceso

c) de equidad.

Los profesionales mediáticos pueden conocer mediante la aplicación de una ficha basada en el Valor Agregado Periodístico el grado de calidad del producto que ofrecen y diferenciarlo de aquellos otros, falsos, engañosos, llamativos, con imagen pero sin fondo, que pueden afectar a la salud psíquica de los espectadores. 
Cuadro 1. Proceso e indicadores del Método VAP

\begin{tabular}{|l|l|l|l|}
\hline Proceso de Selección de la & $\begin{array}{l}\text { Indicadores de Selectividad } \\
\text { Tipo de noticia } \\
\text { Origen } \\
\text { Relevancia }\end{array}$ & $\begin{array}{l}\text { Indicadores de Acceso } \\
\text { Fuentes escritas } \\
\text { Medios } \\
\text { Fuentes personales } \\
\text { Tipo de fuentes }\end{array}$ & $\begin{array}{l}\text { Indicadores de Equidad } \\
\text { Protagonistas } \\
\text { Antagonistas } \\
\text { Temática }\end{array}$ \\
\hline $\begin{array}{l}\text { Proceso de Creación de la } \\
\text { noticia }\end{array}$ & $\begin{array}{l}\text { Indicadores de estilo } \\
\text { Estructura } \\
\text { Atribuciones y citas } \\
\text { Uso de adjetivos } \\
\text { Uso de verbos } \\
\text { Fotos y gráficos }\end{array}$ & $\begin{array}{l}\text { Indicadores de contenido } \\
\text { Antecedentes } \\
\text { Consecuencias } \\
\text { Observación del periodista }\end{array}$ & $\begin{array}{l}\text { Indicadores de énfasis } \\
\text { Datos/ Juicios } \\
\text { Enfoque } \\
\text { Balance }\end{array}$ \\
\hline
\end{tabular}

Fuente: Elaboración propia

En la aplicación de la metodología VAP a varias muestras en el ámbito de la prensa y la televisión existe el objetivo de fijar unos estándares de calidad para la información que contribuyan al fortalecimiento de los productos periodísticos en beneficio de una sociedad mejor informada. 
Cuadro 2. Estándares de Calidad VAP

\begin{tabular}{|c|c|c|}
\hline Estandar CIP & Objetivos & Indicadores \\
\hline 1.- Confiabilidad & Observar el pluralismo del medio & $\begin{array}{l}\text { Tipo de fuentes } \\
\text { Autoridad de las fuentes } \\
\text { Cantidad de fuentes documentales }\end{array}$ \\
\hline 2.- Relevancia & $\begin{array}{l}\text { Observar la importancia de la } \\
\text { información }\end{array}$ & $\begin{array}{l}\text { Grado de impacto en la población. } \\
\text { Situación de los actores de la noticia (estatus) }\end{array}$ \\
\hline 3.- Interés & Observar la proximidad & Cercanía sobre la población objetiva del medio \\
\hline 4.- Proporción & $\begin{array}{l}\text { Si a más impacto/proximidad (IP), más } \\
\text { espacio o tiempo }\end{array}$ & Extensión/FIP (Fuentes, Impacto, Proximidad) \\
\hline 5.- Adecuación & Observar la contextualización & Antecedentes+ Consecuencias \\
\hline 6.- Transparencia & Si el encuadre es el adecuado al tema & Framing \\
\hline 7.- Precisión & Corrección Lingüística & Lenguaje apropiado a la información \\
\hline 8.- Claridad & Gramaticalidad/comprensibilidad & Índice de Flesh \\
\hline 9.- Integración & $\begin{array}{l}\text { Observar el uso de imágenes en relación } \\
\text { con los textos }\end{array}$ & $\begin{array}{l}\text { Cantidad y calidad técnica de imágenes no redun- } \\
\text { dantes del texto }\end{array}$ \\
\hline 10.- Incidencia & Correspondencia con el público & Agenda setting \\
\hline
\end{tabular}

Fuente: Elaboración propia

\subsection{Muestreo y Resultados de Investigación de Fuentes (Prensa)}

La Universidad de Sevilla y dentro de su ámbito el Grupo de Investigación Estudio de Medios para un periodismo de calidad (Sej-001) será el marco en el que se desarrolle el proyecto de análisis de calidad, medición y evaluación de contenidos mediáticos.

El Grupo de Investigación ya ha iniciado el proceso con la aplicación de la herramienta VAP para medir la calidad de las fuentes otorgando una calificación numérica según los niveles aportados por cada uno de los indicadores de la ficha de análisis. Se han seleccionado una serie de diarios locales con trayectoria histórica en la influencia local del lugar en el que se publican como El Correo, La Voz de Galicia, Norte de Castilla, Ideal de Granada, Diario de Sevilla, Hoy (Badajoz), el Heraldo de Aragón y Las Provincias (Valencia). Solo se tratarán las secciones de Local, Economía y Cultura, siendo objetivo de análisis todas las páginas de cada una de estas secciones, pero seleccionando de cada página la noticia principal. 
El muestreo corresponde al periodo comprendido entre el 22 de abril y el 2 de mayo de 2013. El trabajo de campo desarrollado ha consistido en el análisis de 501 informaciones en los ocho diarios seleccionados. Se han leído entre 36 y 80 noticias en cada diario.

Las cuestiones que se han analizado y a las que trata de responder esta fase de la investigación son:

1. Selección de los temas. Agenda Setting.

2. Presencia del periodista en el lugar del acontecimiento

3. Origen institucional o no institucional de las noticias.

4. Iniciativa del periodista o la fuente.

5. Cantidad y calidad de fuentes.

6. Equilibrio de fuentes consultadas y contraste de argumentos.

7. Protagonismo de los temas institucionales frente a los no institucionales

8. Porcentaje de Periodismo de calle, de mesa o de convocatoria.

9. Antecedentes y Consecuencias en el relato de los acontecimientos.

10. Identificación de las fuentes.

Primeros Resultados:

Los resultados obtenidos de las distintas investigaciones realizadas hasta el momento aplicando el procedimiento del Valor Agregado Periodístico se agrupan en función de la temática (institucional o no institucional), de las fuentes (tipología, cantidad y calidad) y de los periodistas (presencia/ausencia, periodismo de calle, de mesa, de convocatorias).

-Respecto a la temática: los periodistas se enfrentan a un vasto número de paraperiodistas, gabinetes de comunicación, empresas de relaciones públicas, portavoces políticos, instituciones públicas, corporaciones u ONGs que apenas dejan tiempo disponible a los periodistas para hablar con sus contactos, cuidar fuentes... seguir temas propios se ha convertido en un lujo. Los periodistas se convierten en receptores pasivos de información en lugar de investigadores activos, con los pies en el suelo e interactuando con su comunidad. Como consecuencia, existe poco interés de los medios por aportar a la audiencia una agenda propia de temas.

Los medios han perdido la iniciativa como generadores de información y lo habitual es que sean las fuentes mismas las que destapan los temas. Las investigaciones analizadas inciden en el protagonismo de las fuentes institucionales: guber- 
namentales, oficiales públicas y oficiales privadas que son las que en definitiva determinan la agenda setting. Esto conlleva la invisibilidad de otras fuentes y de otros temas, la univocidad de los pseudoacontecimientos institucionales gubernamentales y no gubernamentales (ruedas de prensa y convocatorias presenciales y online) que se imponen frente a temas de interés público.

En la investigación sobre fuentes en los periódicos locales citados, de las 501 noticias analizadas, el 46,6\% tratan de un asunto institucional público frente a un 53,6\% que versa sobre otro tipo de temática.

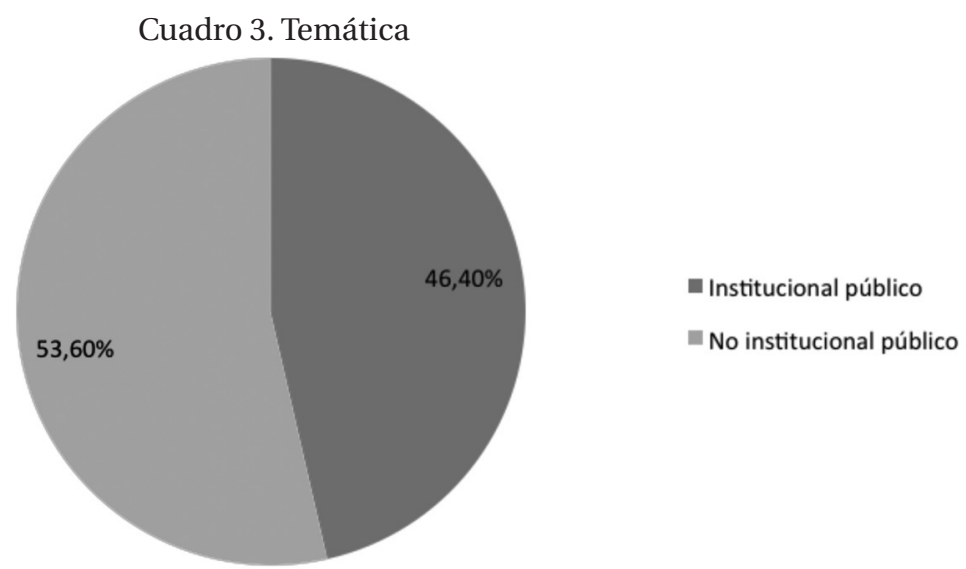

Fuente: Elaboración propia

Además, se comprueba que los medios consideran más valiosas las noticias actuales (políticas y económicas) que las atemporales (sociales y de ocio).

La conclusión derivada de esta variable es el poco interés de los medios por aportar a la audiencia una agenda propia de temas. Los pseudoacontecimientos institucionales gubernamentales (ruedas de prensa y convocatorias presenciales y online) se imponen frente a temas de interés público.

-Respecto a las fuentes: estudiar las fuentes equivale a someter a evaluación un aspecto sustancial del trabajo periodístico. Los datos cuantitativos (número de fuentes por noticia) ya son muy significativos, pero también lo son los que evidencian que el periodista se ha sentido satisfecho con la fuente oficial, institucional, poco plural y unívoca y no ha desarrollado la noticia desde otras perspectivas, con otras fuentes; que en los temas que plantean intereses contrapuestos no se recojan los distintos implicados, a ser posible simultáneamente.

Es necesario saber cuánto se ha recurrido a documentos o se ha contado con expertos; en qué proporción la agenda la han dominado las fuentes que han tomando la iniciativa; si en los temas de iniciativa propia predominan los de una sola 
fuente, lo que viene a significar información irrelevante, intrascendente, si acaso curiosa, en todo caso carente de profundidad.

Todas ellas cuestiones que inciden en la calidad del producto informativo que necesita el ciudadano, tanto más cuando los temas afectan directamente en su vida y sus protagonistas conviven con él. Cuando el periodista se deja atrapar por el círculo de productores interesados de noticias se olvida de que contar lo que pasa obliga a salir de ese círculo e interactuar con el ciudadano y descubrir otra actualidad no menos trascendental.

Es deficiente el número de fuentes consultadas, su diversidad e independencia. La función de gatekeeping o selección de los contenidos no la realizan los medios sino que responde al interés de determinadas fuentes. Las fuentes oficiales ocupan el $61,20 \%$ del total, seguidas de las fuentes personales o no institucionales (26.02\%) y ya en menor proporción las fuentes documentales $(12,53 \%)$ y las fuentes expertas que alcanzan un porcentaje mínimo $(0,2 \%)$. En definitiva, lo habitual es que sean las fuentes las que destapen los temas y controlen la información. Este control de la información por parte de los poderes fácticos redunda en la veracidad, la garantía y la calidad informativa.

\section{Cuadro 4. Tipología de Fuentes}

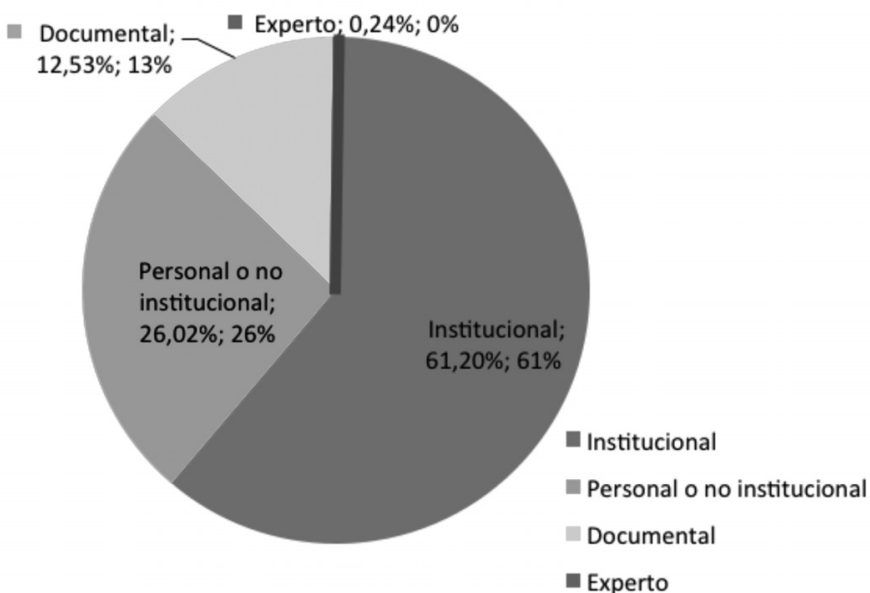

Fuente: Elaboración propia

Así mismo, la fuente ávida o interesada en facilitar y controlar la información alcanza unos porcentajes relevantes sobre todo en el ámbito institucional público frente a la fuente buscada por el periodista que predomina en otro tipo de temáticas. Se trata de un indicador claro sobre el poder de las fuentes en orden a la selección, jerarquización y difusión de los contenidos periodísticos. La fuente ávida se relaciona muy directamente con los llamados pseudoacontecimientos (rue- 
das de prensa y convocatorias) que se centran en potenciar e imponer unos hechos noticiosos, desviar la atención y reducir la capacidad de denuncia del medio.

Por otro lado, la cantidad de fuentes consultadas es también un factor de calidad. En el estudio no se ha considerado como fuente al propio periodista. Así, de las 501 noticias analizadas, el número medio de fuentes detectadas ha sido de casi dos. No obstante, el 49,3\% de las informaciones vienen sustentadas por más de una, mientras que el 8,6\% de las noticias carecen de ellas.

Como norma general se suele incluir un único punto de vista, lo que da cuenta de que no existe un certero contraste de la información y se refuerza una sola visión sobre el tema, sin dar participación a otras voces que difieren de este. Así, aunque se utilicen distintas fuentes, se sustenta solo una posición, lo cual es a todas luces, sesgado e inequitativo (García Gordillo, M, Bezunartea, O. y Rodríguez Cruz, I., 2013: 49).

Cuadro 5. La calidad según el número de fuentes

Número de fuentes

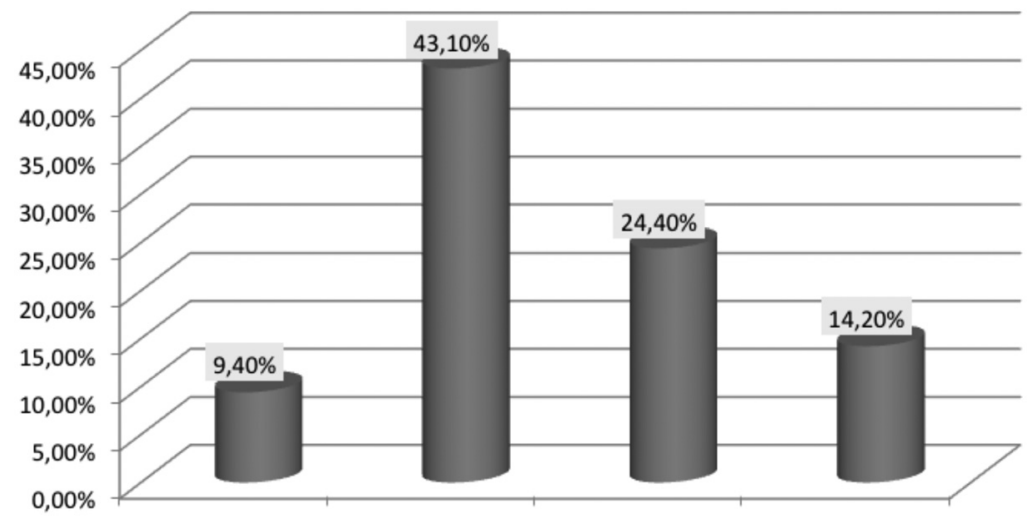

Fuente: Elaboración propia

Como vemos en el gráfico anterior, el número de fuentes predominante en las informaciones es una sola fuente $(43,1 \%)$, se usan dos en un $24,4 \%$ de las noticias, tres en un $14,2 \%$ y cuatro en un $9,4 \%$ de los casos.

c) Respecto al papel de los profesionales: si partimos de que los medios y por ende, los periodistas han dejado de buscar información y de utilizar fuentes propias, ¿qué ofrecen en su trabajo diario?

La investigación previa en prensa pone de manifiesto que frente a la presencia del periodista en el lugar de los hechos, la información está muy condicionada por el Periodismo de mesa o de convocatoria. 
Cuadro 6. Presencia in situ del periodista

\begin{tabular}{|l|c|c|}
\hline Presencia & Frecuencia & Porcentaje \\
\hline Periodismo de calle & 179 & 35,7 \\
\hline Convocatorias & 155 & 30,9 \\
\hline Periodismo de mesa & 162 & 32,3 \\
\hline Relato impreciso & 5 & 1,0 \\
\hline Total & 501 & 100,0 \\
\hline
\end{tabular}

Fuente: Elaboración propia

Como se puede comprobar en la tabla anterior el Periodismo de calle ocupa el primer lugar (179 noticias) frente a la opción Periodismo de mesa (162) y de convocatorias (155). Sin embargo, cuando se analizan secciones específicas de Política, Economía o Cultura en el ámbito de periódicos locales de referencia se observa que hay una tendencia del periodista a realizar su trabajo desde la mesa de redacción incluso cuando la cercanía a los hechos, propia del Periodismo de proximidad, sería un argumento de fuerza para acudir al lugar de los acontecimientos, observar la actitud de las fuentes, analizar y contrastar la información, lo que favorece la transparencia y la veracidad informativa.

En general no procesan en exceso las informaciones de las fuentes, lo que conlleva un uso excesivo de la estructura en pirámide invertida. Elevada tendencia a subjetivar los hechos y alto promedio de verbos de atribución (decir, afirmar, agregar...) lo que supone que se transcribe lo dicho por la fuente sin procesarlo. Se observa además en porcentajes elevados el uso de adjetivos y adverbios valorativos lo que indica una peligrosa tendencia a dejar que los juicios del periodista entren a formar parte de la información.

Algunos retos para la mejora de la calidad periodística conducen a preguntarse cómo la proximidad ante el acontecimiento puede mejorar el producto informativo, entendiendo el concepto de proximidad desde diversos puntos de vista: el físico, estar en el lugar de los hechos o el social, en cuanto a interés por lo próximo.

Otro aspecto mejorable sería el que permita medir las cualidades individuales de los periodistas y lo que aportan al producto informativo.

\section{Conclusiones de la investigación en prensa}

Los resultados de la investigación de base sobre tratamiento de las fuentes periodísticas en diarios españoles de referencia de ámbito local derivan en las siguientes conclusiones: 
- $\quad$ Sigue siendo habitual un uso excesivo del Periodismo de Declaraciones, de Mesa y de Convocatoria frente a la poca presencia directa del periodista en el lugar de los hechos.

- En la mayoría de las noticias seleccionadas se consulta a una única fuente que además procede del ámbito institucional gubernamental. Son pocas las informaciones que cuentan con dos o más fuentes lo que pone en tela de juicio el contraste, la verificación y la transparencia del relato.

- También habría que resaltar el interés por informar de la fuente ávida procedente del ámbito institucional público lo que incide en el control de la agenda mediática por parte de los poderes políticos.

- Los pseudoacontecimientos (ruedas de prensa, notas y convocatorias) siguen ocupando un porcentaje importante en la agenda periodística.

- $\quad$ Hay que destacar que la mayoría de las fuentes aparecen identificadas.

- S Se detecta una buena contextualización de los hechos así como la inclusión de datos antecedentes (background) y consecuentes que ayudan a los lectores a conocer las causas.

- El factor proximidad favorece la presencia del periodista en el acontecimiento así como el acceso directo a la fuente y la posibilidad de contraste y verificación lo que redunda en el incremento de la calidad informativa.

En relación con estas conclusiones se aportan algunas recomendaciones de interés para los medios:

a) Los periodistas no deben escribir para las fuentes sino para el público.

b) Hay que responder a todos los interrogantes que la propia información le sugiere al lector.

c) Cuanto más próxima sea la noticia, más obligación tiene el periodista de cumplir con los requisitos de calidad y de comprobación de los datos. Es mucho más fácil que los receptores detecten los errores y fallos en la proximidad de los hechos.

d) Las fuentes oficiales exponen sus decisiones. Le corresponde al periodista complementarlas desde el punto de vista de los afectados.

e) Los periodistas deben preocuparse de si sus informaciones están mayoritariamente basadas en declaraciones y discursos y no en hechos.

\section{Propuestas de investigación. Niveles de calidad en informativos de televisión pública}

A partir de esta investigación inicial se desarrollarán diferentes aplicaciones de la ficha VAP. En concreto, la siguiente fase y propuesta de investigación tiene como objetivo baremar la calidad de los contenidos en el ámbito de la Televisión Pú- 
blica. Se seleccionarán programas informativos de distintas cadenas que posibiliten comparar los índices de calidad en el tratamiento de noticias de carácter político, económico y cultural. Operadores públicos como Televisión Española y Canal Sur TV serán objetos de referencia. Esta segunda fase de la investigación se iniciará en el curso 2014-2015 y permitirá además comparar resultados en distintos ámbitos mediáticos.

Los resultados permitirán comprobar qué índices de calidad alcanzan los telediarios en el tratamiento de la información de carácter político, económico y cultural. El tratamiento de los contenidos, uso de las fuentes, del lenguaje, los horarios de emisión, conductores del programa, discurso, uso de recursos audiovisuales, tiempos de publicidad son variables contempladas en la ficha. El cruce de variables y la comparación de resultados entre operadores servirán para comprobar que existen periódicos, programas de radio y televisión que responden mejor a una información rigurosa, interesante y capaz de formar y entretener a los públicos.

Los propios medios, autores de la noticia y organismos reguladores del Audiovisual tendrán acceso a las conclusiones sobre la calificación obtenida de forma que puedan aplicar en cada caso las recomendaciones del informe.

-Ficha VAP. Certificado de Calidad Mediática

El proceso comienza con el análisis de la información en distintos soportes (prensa, radio, televisión o Internet) siguiendo el modelo de ficha VAP. Los resultados de la investigación mostrarán a los medios evaluados los índices de calidad obtenidos y posteriormente en la etapa formativa correspondiente se explicará a los autores de la noticia, los periodistas, cómo se ha realizado el trabajo y las razones objetivas a las que responde.

La ficha de análisis comprende unos valores cuantitativos pero introduce otros valores más concretos que dependen de la actitud del periodista ante la información; es decir, el periodista es productor de la noticia y como tal la enfoca, la estructura, contacta con unas fuentes y obvia otras (respondiendo a intereses particulares o de estancias más elevadas internas y externas al medio), explica, analiza, interpreta y a veces realiza una valoración crítica (argumentada o no) de la información.

También se puede dar el caso contrario y encontrar que la información solo responde a una estructura de titulares, de pirámide invertida, no contrastada, exenta de explicación, interpretación o análisis, sensacionalista, sin interés público...

No existe aún una plantilla que aplicada al abanico de información que ofrecen los medios tenga como resultado una valoración cuantitativa y cualitativa de lo producido por los periodistas. Se trata de demostrar al periodista con unos criterios objetivos los niveles de calidad de su información. 
Cuadro 7. Ficha de Análisis de Noticias en Informativos de Televisión

\begin{tabular}{|c|c|c|c|c|}
\hline MEDIO & CONTENIDOS & PERIODISTA & FUENTES & LENGUAJE \\
\hline Nombre & Título y Subtítulo & Firma & Número y calidad & $\begin{array}{l}\text { Tipo: Informativo/Inter- } \\
\text { pretativo/ } \\
\text { Opinión }\end{array}$ \\
\hline Programa & $\begin{array}{l}\text { Referencia a la } \\
\text { fuente }\end{array}$ & Hombre/Mujer & Tipología & Técnico/Coloquial \\
\hline Sección & $\begin{array}{l}\text { Acontecimiento for- } \\
\text { tuito o provocado }\end{array}$ & $\begin{array}{l}\text { Periodista de un } \\
\text { medio, agencia, co- } \\
\text { rresponsal, otros }\end{array}$ & $\begin{array}{l}\text { Uso: suficiente o insu- } \\
\text { ficiente }\end{array}$ & $\begin{array}{l}\text { Tecnicismos, Extranje- } \\
\text { rismos, Siglas, } \\
\text { Acrónimos }\end{array}$ \\
\hline Ámbito Geográfico & Enfoque & Presencia /Ausencia & Atribuciones & Decodificación \\
\hline Tema & $\begin{array}{l}\text { Tema: Institucional } \\
\text { o No Institucional }\end{array}$ & $\begin{array}{l}\text { Seguimiento: conti- } \\
\text { nuado o esporádico }\end{array}$ & $\begin{array}{l}\text { Protagonismo e inicia- } \\
\text { tiva de la fuente }\end{array}$ & $\begin{array}{l}\text { Tratamiento de grupo } \\
\text { de riesgo: menores, mu- } \\
\text { jeres, ancianos y } \\
\text { discapacitados }\end{array}$ \\
\hline $\begin{array}{l}\text { Información Principal } \\
\text { o Secundaria }\end{array}$ & Antecedentes & $\begin{array}{l}\text { Iniciativa del perio- } \\
\text { dista o de la fuente }\end{array}$ & $\begin{array}{l}\text { Intereses } \\
\text { contrapuestos }\end{array}$ & $\begin{array}{l}\text { Discurso: sensaciona- } \\
\text { lista, falaz, morboso, } \\
\text { racista, crítico }\end{array}$ \\
\hline $\begin{array}{l}\text { Espacio y Tiempo de la } \\
\text { Noticia }\end{array}$ & Consecuencias & $\begin{array}{l}\text { Equilibrio y contraste } \\
\text { de fuentes }\end{array}$ & $\begin{array}{l}\text { Narrador } \\
\text { Testigo, beneficiada } \\
\text { perjudicada }\end{array}$ & $\begin{array}{l}\text { Uso de tópicos, estereo- } \\
\text { tipos y falacias }\end{array}$ \\
\hline Uso de Publicidad & $\begin{array}{l}\text { Relación con otros } \\
\text { hechos }\end{array}$ & $\begin{array}{l}\text { Uso de recursos com- } \\
\text { plementarios: } \\
\text { fotografía, infografía, } \\
\text { fotonoticia, gráficos }\end{array}$ & $\begin{array}{l}\text { Identificación de la } \\
\text { fuente }\end{array}$ & $\begin{array}{l}\text { Lenguaje audiovisual: } \\
\text { uso de recursos gráficos, } \\
\text { imágenes de archivo, en } \\
\text { directo, de relleno, apro- } \\
\text { piadas o inapropiadas }\end{array}$ \\
\hline
\end{tabular}

Fuente: Elaboración propia

-Muestra y aplicación de la ficha

El corpus de la investigación presenta las siguientes características: 
El modelo de ficha presentado se aplicará durante dos semanas consecutivas a los informativos emitidos por Televisión Española en la franja de las 15 horas y Canal Sur TV en la franja de las 14,30 horas respectivamente. La fecha establecida será desde el 1 al 15 de diciembre de 2014. El número de unidades analizadas corresponderá a todas las noticias principales de carácter político, económico y cultural emitidas por estas cadenas durante el tiempo establecido de investigación.

El formato de la ficha VAP permitirá seleccionar más de una respuesta y obtener los niveles numéricos y porcentuales de calidad relativos a la información analizada. La ficha puede adaptarse a la investigación de cualquier temática con el objetivo de medir la calidad en los medios: uso de las fuentes, pluralismo político, inmigración, estudios de género, menores, sucesos... así como a cualquier tipo de programa: informativo, editorial, reality, magazine, debate, infantil, tertulia, series...

La ficha potencial recoge una serie de variables cuantitativas y cualitativas que pueden explicar la actitud de los periodistas y de las fuentes seleccionadas en la producción de la información y sus consecuencias en los receptores, en función de su edad, su formación, su nivel social, su ideología...

Existen unos bloques generales de medición: Medio, Contenidos, Fuentes y Lenguaje. Cada uno de estos bloques recoge unos ítems o valores de medición que se tratarán de forma independiente, combinada por cruce de variables e interrelacionada para que confluyan los resultados finales.

En el plano de la televisión y aunque existen investigaciones preliminares, el formato se aplicará a informativos diarios en su emisión de la 1 emitidos por dos cadenas públicas, una de ámbito nacional (Televisión Española) y otra de ámbito regional (Canal Sur TV) para comprobar los valores y sobre todo extraer conclusiones sobre la necesidad de formación de los periodistas para diseñar calidad.

De la aplicación de la ficha de medición se derivarán los correspondientes resultados y conclusiones que permitirán comparar el rol del periodista y de las fuentes en el ámbito de la prensa y de la televisión ante el tratamiento diario de los acontecimientos y lo que es más importante: si la calidad informativa está vinculada al buen quehacer profesional del periodista y en definitiva de su medio.

El Grupo de investigación se plantea también elaborar un informe con los rankings de calidad informativa alcanzados por los medios analizados, que podrán conocer las propias empresas porque en definitiva será útil para rectificar y en su caso formar parte de las empresas más prestigiadas y con mayor garantía profesional de su ámbito.

Además, con objeto de conocer la opinión de las fuentes directa o indirectamente afectadas por los medios de comunicación y la red, también se plantea como complemento al análisis de contenido la realización de entrevistas a diferentes sectores: 
-La familia

-Los menores y los jóvenes

-Los profesionales mediáticos

-Los educadores

-Los organismos reguladores del audiovisual

El objetivo final es interrelacionar los resultados de fichas de análisis con encuestas sobre el uso que hacen los menores y los jóvenes de la televisión y de Internet, para definir las conclusiones finales del estudio respecto a los niveles de calidad de los medios, la opinión de la ciudadanía y la acción de la Educación Mediática sobre ambos.

A partir de los resultados, los propios medios podrán conocer de manera cuantitativa y cualitativa el nivel de calidad en el tratamiento de las noticias, su implicación en el número, equilibrio y el contraste de las fuentes consultadas, si la información incluye antecedentes y está correctamente contextualizada, entre otras variables.

Los medios necesitan auditarse a partir de una medición científica que les demuestre si pueden considerarse "marca mediática de calidad", divulgadores de un producto que no dañe al consumidor y que responda a la responsabilidad social que se les exige. Nuestra meta: aportar datos rigurosos y significativos que ayuden a los medios a cuestionar su labor y responsabilidad y sobre todo a mejorar la calidad periodística. No como recomendación sino como exigencia de los ciudadanos.

\section{Referencias bibliográficas}

Alsius, S. (2011): “Cap a una gran base de dades per a l’estudi de l’ética periodística”, Periodística, 13, pp. 27-58

De la Torre, L. y Téramo, M. T. (2005): “Medición de la calidad periodística: La información y su público”, Doxa, n. 3, pp. 173185.

García Gordillo; M. Bezunartea, O. y Rodríguez Cruz, I. (2013): "El valor agregado periodístico, herramienta para el periodismo de calidad" en Gómez Mompart, J. L, Gutiérrez Lozano, Juan F. y Palau Sampío, D. (Eds): La calidad periodística. Teorías, Investigaciones y sugerencias profesionales. Barcelona: Servicio de Publicaciones de la UAB, pp. 39-52.

Gómez Mompart, J. L. (2001): “Periodismo de calidad para una sociedad global”, Pasajes, 7, (www.revistasculturales.com), pp. 25-35. [Consultado el 12/09/2014].

Gómez Mompart, J. L. y PalauSampío, D. (2013): "El reto de la excelencia. Indicadores para medir la calidad periodística" en Gómez Mompart, J. L.; Gutiérrez Lozano, Juan F. y Palau Sampío, D. (Eds): La calidad periodística. Teorías, Investigaciones y sugerencias profesionales, Barcelona: Servicio de Publicaciones de la UAB, pp. 17-38. 
Gutiérrez Coba, L. (2006): Análisis de la calidad informativa, primer paso hacia el cambio. Colombia: Universidad de La Sabana, pp. 29-56.

Israel Garzón, E. y Pomares Pastor, R. A. (2013): “Indicadores de calidad en los informativos de televisión” en Gómez Mompart; J. L, Gutiérrez Lozano, Juan F. y Palau Sampío, D. (Eds): La calidad periodística. Teorías, Investigaciones y sugerencias profesionales, Barcelona: Servicio de Publicaciones de la Universidad Autónoma de Barcelona, pp.147-161.

Krippendorff, K. (1990): Metodología del análisis de contenido. Teoría y práctica. Barcelona: Paidos.

Lewis, J. et. al. (2007): The Quality and Independence of British Journalism, Cardiff School of Journalism, Media and Cultural Studies, UK: Universidad de Cardiff.

Téramo, M. T. (2006): “Calidad de la información periodística en Argentina. Estudio de diarios y noticieros”, Palabra Clave, n. 9, pp. 57-84.

VV.AA. (2006): Propuesta de indicadores para un periodismo de calidad en México, Cuadernos de Información, (www.revistasdecomunicacion.org/r_cuadernos_informacion.html), 14, pp. 36-37 [Consultado el 12/09/2014].

VV.AA. (2001):VAP. “Un sistema métrico de la calidad periodística”, Cuadernos de Información, 14, (www.revistasdecomunicacion.org/r_cuadernos_informacion.html), pp. 112-120. [Consultado el 12/09/2014].

Vázquez Barrio, T. (2011): ¿Qué ven los niños en la televisión?, Madrid: Editorial Universitas, pp. 119. 